\title{
EPIPHYSIOLYSIS OF THE GREAT TUBEROSITY OF THE CALCANEUM: BRIEF REPORT
}

\author{
J. L. ALVAREZ FERNANDEZ, M. VILLALBA VAQUERO, J. GOMEZ CIMIANO
}

We report a case of epiphysiolysis of the great tuberosity of the calcaneum in a 10-year-old patient and discuss the mechanism, the surgical treatment and the result. A fracture-separation of this nature at this age has not, as far as we know, been reported previously.

Case report. A 10-year-old girl complained of spontaneous acute pain in the left heel. There were no other symptoms and the radiograph showed only minor abnormalities (Fig. 1). The pain settled with rest and analgesics but six months later it recurred, with progressive heel deformity and reduced ankle movements. On examination there was non-tender swelling of the left heel and no external signs of inflammation. A new radiograph showed separation of the great tuberosity of the calcaneum through the growth plate, with considerable displacement (Fig. 2). CT scans gave no further information.

At operation the tuberosity was replaced and secured with screws. Since the foot was then in extreme equinus, Z-lengthening of the calcaneal tendon was also performed. The ankle was held at $90^{\circ}$ in plaster for five weeks, and physiotherapy was then given for a further five weeks. The end result was satisfactory, both for appearance and function.

Discussion. Fractures of the calcaneum in children are very rare, Zayer (1969) reporting only one case in a 12year-old in his series of 110 patients. We could find no previous report of separation of the tuberosity, especially in the absence of a clear history of trauma.

Our patient was fond of skipping; this was the only possible activity which could be blamed, and it is possible that repeated microtrauma caused by jumping and landing on the toes, with sudden contractions of the triceps, could have produced separation and displacement. Stress fractures of the calcaneum are very rare in adults (Hullinger 1944) and even more rare in

J. L. Alvarez Fernandez, MD

M. Villalba Vaquero, MD

J. Gomez Cimiano, MD

Departamento de Traumatologia y Ortopedia, Hospital Nacional

"Marques de Valdecilla", 39008-Santander, Spain.

Correspondence to Dr J. L. Alvarez Fernandez.

(C) 1989 British Editorial Society of Bone and Joint Surgery $0301-620 X / 89 / 2$ R99 $\$ 2.00$

J Bone Joint Surg [Br] 1989;71-B:321.

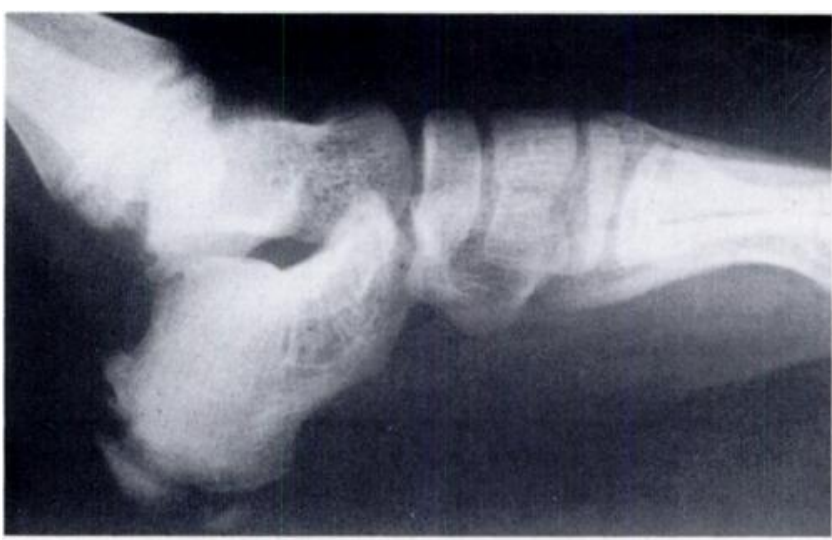

Fig. 1

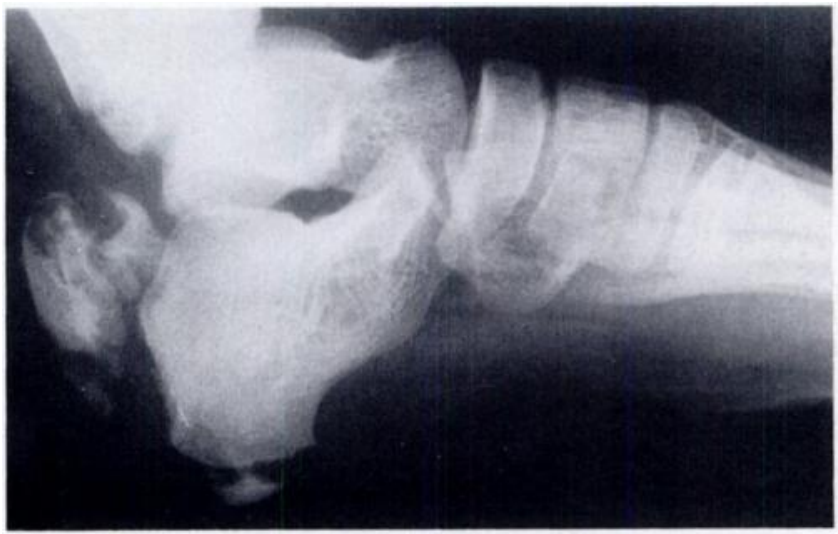

Fig. 2

children. Stein and Stelling (1977) and Buchanan and Greer (1978) reported only one case each, neither of them displaced. Epiphysiolysis probably caused by repeated stress has never to our knowledge previously been described.

No benefits in any form have been received or will be received from a commercial party related directly or indirectly to the subject of this article.

\section{REFERENCES}

Buchanan J, Greer RB III. Stress fractures in calcaneus of a child: a case report Clin Orthop 1978;135:119-20.

Hullinger CW. Insufficiency fracture of the calcaneus: similar to march fracture of the metatarsal. J Bone Joint Surg 1944;26:751-7.

Stein RE, Stelling FH. Stress fracture of the calcaneus in a child with cerebral palsy. J Bone Joint Surg [Am] 1977;59-A:131.

Zayer M. Fracture of the calcaneus: a review of 110 fractures. Acta Ortho Scand 1969;40:530-42. 